\title{
Comparison of Enterprise Framework Architecture in Msmes Manufacturing Sector
}

\author{
${ }^{1 \text { st AprianaMarselina }}$ \\ Dept. FakultasEkonomi \\ Universitas Flores \\ Ende, Indonesia \\ E-mail: Aprilradja82@gmail.com
}

\author{
${ }^{2 n d}$ MelkyRadja \\ Dept. FakultasTeknologiInformasi \\ Universitas Flores \\ Ende, Indonesia \\ E-mail: Melky.radjastudy@gmail.com,
}

\author{
${ }^{3 r d}$ FerdinandusLidangWiti \\ Dept. FakultasTeknologiInformasi \\ Universitas Flores \\ Ende, Indonesia \\ E-mail: ferdylidang2017@gmail.com
}

\begin{abstract}
In business, managing information technology systems is one of the supporting factors in increasing business value, which can be done through a good system architecture planning and design process. To achieve this, information systems that exist in a business must be managed with the right enterprise architecture method. This paper will discuss the enterprise architecture model that can be used including the ZACHMAN Framework, and the TOGAF Framework. This study builds a system architecture design using two enterprise architecture models based on their respective frameworks on Micro, Small \& Medium Enterprises (MSMEs) in the manufacturing sector, and comparing the performance of the two models. This study aims to assist entrepreneurs in the field of MSMEs, especially the manufacturing industry sector that does not yet have a business architecture in order to develop their business through the application of the appropriate enterprise architecture model. The results of this study prove that the implementation of TOGAF in MSMEs in the manufacturing sector is more effective than Zachman.
\end{abstract}

Keywords: Information Technology Management, Enterprise Archithecture, MSMEs.

\section{INTRODUCTION}

Enterprise architecture was first started in 1987 through the publication of the IBM System Journal "A Framework for Information System Architecture" by J.A. Zachman [1]. In this journal, Zachman said that the success of a business depends on how to organize information and manage every system that exists in the business itself. The Zachman framework introduces the conceptualization of architecture from various perspectives such as objectives / scope, enterprise models, systems models and technical models, using different architectural descriptions. Zachman uses an entity relationship model to describe the data and uses a functional flow chart to describe the process. Enterprise Architecture Management (EAM) also aims to maintain flexibility, cost efficiency and transparency within a company and addresses an effective and efficient Business-IT transition [2].

Enterprise architecture is a process of business organization, strategic perspective, information, services, applications, technology and information technology infrastructures that are integrated and standardized depending on the company's vision, mission and operational model. [3]. Alignment between business and information systems is a major problem in any organization, including aspects in a company's architecture that contribute to the strategy or how changes in it can support the implementation of the strategy. In business strategy, an important issue is how information technology can enable the achievement of competitive and strategic advantages for the company [4].

MSMEs is one type of enterprise profit that is able to support the development of the country's economy. According to data from the Ministry of Cooperatives and MSMEs in 2017 [5] the development of the number of MSMEs in Indonesia reached $62,922,617$ units, more than the types of large businesses, namely 5,460 units. Judging from the number of workers produced by MSMEs in 2017 reached $120,260,185$ people, while in the type of large businesses it reached 3,586,769 people. Among the developments that were so good in the types of MSMEs businesses there were various obstacles that were found, including that the business continuity did not last so long, fund management, and poor organizational governance made new entrepreneurs in MSMEs choose to stop continuing the business that had already started. Enterprise Architecture can be a good solution in helping develop business frameworks and strategies.In this paper, we try to see what Enterprise architecture framework is appropriate and effective to be applied in MSMEs, seen from a comparison of each model of an enterprise architecture framework based on existing views and aspects, to support MSME entrepreneurs in developing their business.

\section{RESEARCH METHODS}

\section{A. Micro, Small and Medium Enterprises (MSMEs)}

Based on the International Standard Classification of All Economic Activities (ISIC)[6]MSMEs are classified according to the type of business sector including: Agriculture, Farming, Forestry and Fisheries, Mining and Quarrying, Processing Industry, Electricity, Gas and Clean Water, Buildings, Trade, Hotels and Restaurants, Transportation and Communication, Finance, Leasing and Corporate Services, Services. 
MSMEs itself there are many obstacles that can affect the development of MSMEs [7]. These constraints include internal constraints which include problems of capital, human resources (labor), raw materials and poor financial accounting systems, other obstacles are external constraints which include a business climate that is not yet conducive, for example lack of coordination between MSME stakeholders , structuring business locations, large transaction / business costs, other external constraints are the limited technological infrastructure facilities and have not been able to keep up with the rapid changes in consumer tastes.

\section{B. MSMEs in the Manufacturing Industry Sector}

The processing industry is one of the MSME sectors that carries out economic activities in processing raw goods into semi-finished or finished goods. According to the LPPI (Indonesian Banking Development Institute) [8]The things that need to be considered in the development of MSMEs in the processing industry sector include: Business location and licensing, whether the company operates based on orders from other companies, ownership status, technology and machine capacity related to production plans, experts include design, finishing and machines, quantity, quality and continuity of workforce. The LPPI also describes the financial profile of the processing industry business which includes assets, business turnover, cash flow, and cost structure and operating income. In Figure 1, the LPPI describes the value chain for the processing industry business.

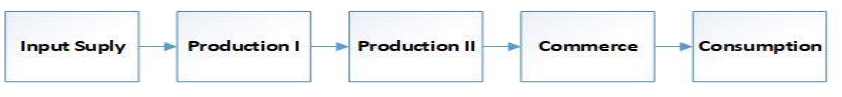

Fig. 1: The Manufacturing Business Value Chain

\section{Zachman Framework}

Basically the Zachman Framework is an ontology or a theory about the existence of a set of important components, which are structured from an object that requires an explicit expression and can create, operate, and convert certain objects into objects such as companies, departments, solutions, projects, buildings, products, or whatever. The Zachman Framework is represented by a $6 \times 6$ matrix, which describes the intersection of the two-dimensional system architecture classification [9]. Whereas the information system is divided into three major components including data, process, and technology[10].

\section{The Open Group Architecture Framework (TOGAF)}

TOGAF is a model in the development of enterprise architecture, TOGAF sees enterprise architecture as a unified architecture from the most general level to a more specific level. The general principle of the TOGAF framework architecture that can be used by any IT organization is Foundation Architecture, where the Foundation Architecture is a general service architecture and functions that provide the foundation on which more specific architecture and architectural components can be built. For a more specific level, Common Systems Architectures are architectural

principles that can be used for various types of IT organizations but not all organizations can use these principles. The next specific levels are Industry Architectures, and Organizational Architectures. In enterprise architecture, TOGAF framework has 3 main pillars of Enterprise architecture domains, Architecture Development Model $(\mathrm{ADM})$, and Enterprise Continuum.

\section{RESULTS AND DISCUSSION \\ A. Implementation of Enterprise Architecture}

\section{Planning}

Planning is needed in explaining the objectives between organizations and information technology in supporting decision making, increasing the effectiveness of organizational operations, and increasing data integrity between every part of the organization. In building an enterprise architecture, things that must be considered are the type of organization and the needs of the organization. Every architectural model making must first formulate the needs of the organization in order to build an information system architecture model that is useful in achieving the vision and mission.

\section{Determination of the Appropriate Enterprise Architecture Model}

This section will explain about examples of the implementation of the TOGAF framework and the Zachman Framework at MSMEs. This is done to see what type of framework is more suitable or effective in building Enterprise Architecture.

\section{a) Zachman Framework Application}

The architectural model design is based on Zachman's framework, namely: What, How, Where, Who, When, and Why, with determinations based on: Planer (maker of scope / objective), Owner (Maker of Enterprise Model), Designer (maker of information system model design), Builder (maker of technology model design), Programmer (Maker detail system / system analysis), and enterprise functions.

\section{i. $\quad$ Data Architecture $\rightarrow$ What}

In designing a data architecture, the specification of data requirements must be described in detail to answer all business needs. In this study, we will try to provide examples of input from planers regarding the data needed, including buyer data, transaction data, and product data. Meanwhile, from the designer's point of view, examples of existing data entities are given at MSMEs. The intended data entity includes consumer data (id_customer, name_customer, address, no_hp), 
Product (id_product, name_product, old_price, new_price, discount), Transaction (Id_customer, id_product, order_code, item_count, payment_option). From a builder's point of view, is depicted using the science diagram in Figure 2.From the programmer's point of view or the details of the system, it can be seen in the data description in Figure 2. While from the point of view of the enterprices function, it can be seen in Figure 3 which explains the details of business functions.

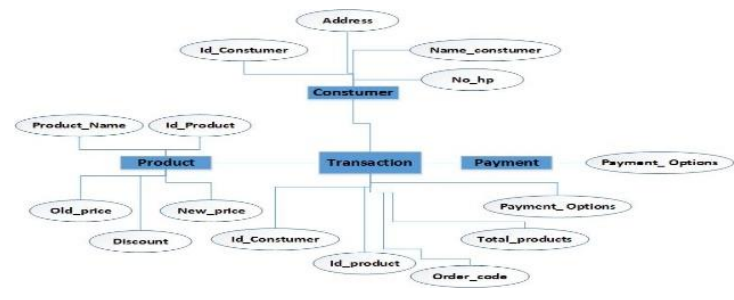

Fig. 2. ERD Business Process

In Figure 2, it is explained about the ERD of business processes in processing industry MSMEs. Processing industry business processes generally include the production of raw materials to the sales process. One of the main sources of income in the processing industry is the sale of products, while other income sources are from borrowing capital. For this reason, in the process of developing the processing industry, Figure 2 describes the ERD of the business process in terms of sales of products. In Figure 2, every detail of available data information has a role in the overall sales reporting process. This is intended so that there are no errors in the calculation of sales results such as production stocks that were successfully sold, customer data, and being able to estimate the next production amount based on the history of previous sales results.

\section{ii. Application Architecture $\rightarrow$ How}

At this stage, it is explained about how the system process, purchasing activities, sales and purchase process flow are more detailed as planned according to the planner, builder, designer, owner, programmer, and enterprise function perspective described in Figure 3.

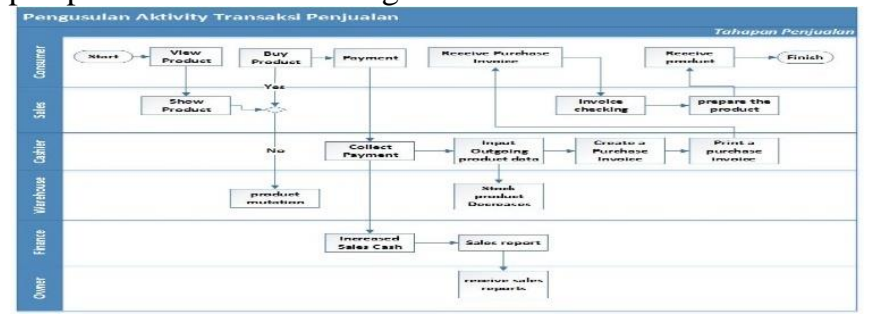

Fig. 3. Sales Transaction Activity

Figure 3 explains the role of each department in the processing industry in the process of selling products, such as the role of consumers, owners, financial administrators, warehouse officers, cashiers, and marketing officers. Each process in the existing transaction system has advantages in terms of reporting which have the goal of recording and analyzing all activities for further business development.

\section{iii. Technology Architecture $\rightarrow$ Where}

At this stage, it explains the definitions of the main technology used in supporting enterprise systems that are built from the perspective of the planer (explanation of the devices used in table 1), designer (technology architecture flow in supporting sales and purchasing activities), Builder (proposing a technology architecture model in Figure 5).

TABLE I. DETAILS OF TECHNOLOGY DEVICES

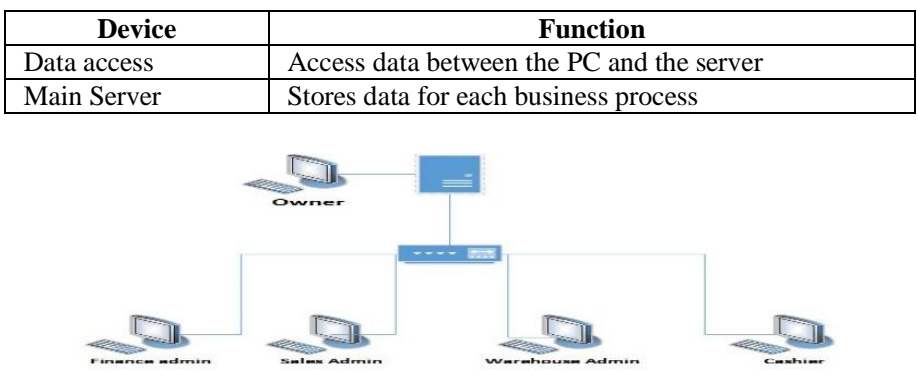

Fig. 4. Conceptual Network for MSMEs

Figure 4 describes the technology network architecture applied in the processing industry business. Some of the technological devices used include: a computer that functions as a desktop-based information system installation medium, a switch as a liaison between each computer that has been installed and a server that is a data storage medium or database for every activity in the information system. The server can only be accessed by the business owner to anticipate the use of business information.

\section{b) TOGAF-ADM Application}

This stage is the implementation of the TOGAF framework design in the Manufacturing Industry sector according to the MSME organizational standards.

\section{i. Preparation phase}

a. Scope of business: Processing industry business which covers business activities in production and sales.

b. Organizational Structure of MSMEs in Figure 5, it is explained that the structural MSMEs in the processing industry sector in general. 


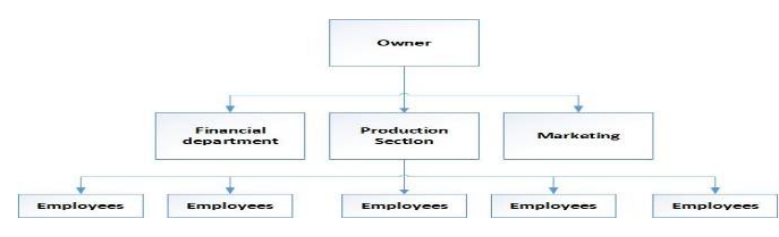

Fig. 5. Organizational Structure of MSMEs

In this preparation stage, the organizational structure of the processing industry MSME must be known to be able to build a suitable framework. Figure 5 describes the most common organizational structures in the manufacturing industry. In the organizational structure, it consists of business owners and employees or workers who have tasks including the financial department that functions as an assistant in financial reporting, the production department that functions as a product maker from raw materials to finished goods or ready-to-sell products, and the marketing department which serves to market the products. Each part and function of this organization will later be used as information in building the desired information system framework.

\section{ii. Architecture Target}

The purpose of this architectural development is to improve the processing industry business development process based on work principles, organizational structure and achievement of the vision and mission. The target to be achieved in architectural design can be seen in Figure 7. Through the application of information systems into business processes.

Figure 6 describes the target architecture that is built based on the information obtained. In building the enterprise architecture the main target is planned to be divided into parts, the first is to determine the vision, mission, business strategy, business scope or domain, solutions, and implementation.

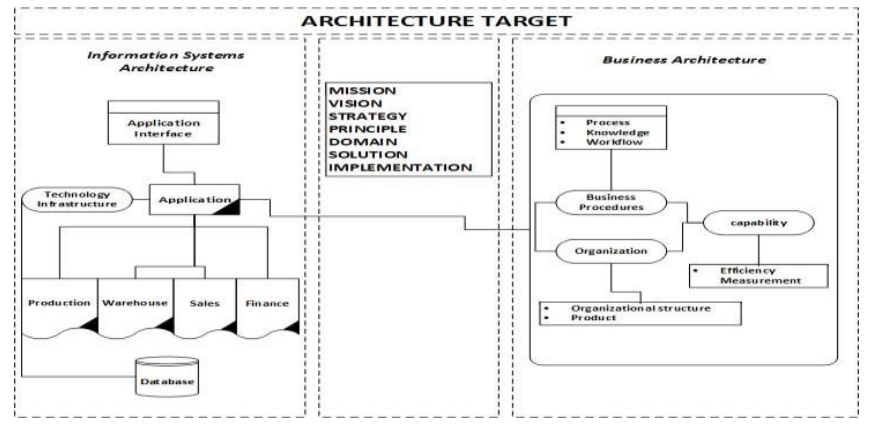

Fig. 6.Architecture Target

The second plan is a business architecture to determine the steps used in business processes, including work flow, business procedures, organizational structure, products, and business efficiency measurements. For the third plan is planning an information system architecture that functions to apply the entire business process that runs into a structured and corporate system.

\section{iii. Architecture Vision}

This phase will explain the business value chain that exists in the processing industry business. Some of the scopes that exist in processing industry-type MSMEs can be seen in Figure 7. The main functions of MSMEs are: Input Supply: includes industrial raw materials, industrial supporting materials such as production machines and other materials. Production I: is the result of semi-finished production. Production II: is the result of production or finished goods, the finishing process, and the packaging or brand process. Trade: includes the sale of products or distribution of products. Consumption: is the use of products by consumers.

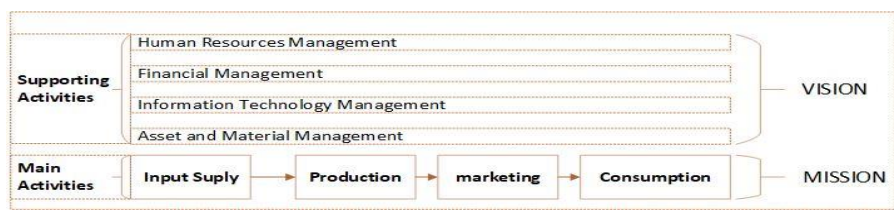

Fig. 7. MSME business value chain in the manufacturing sector

In achieving business goals, a structured and planned processing step is required according to the vision and mission to be achieved. Figure 7 describes the steps for the activities carried out in the processing industry business process. These activity steps will form the basis for building the next business architecture. The information system development process will try to implement support activities into the system to help the main activities succeed in achieving the expected values.

\section{iv. Business Architecture}

In this phase, the business model used in MSMEs will be explained. In general, the business model in the processing industry sector MSMEs is as follows: Owner (finance): creates and sends invoices according to sales orders and receives payments. Production: making products, delivering products. Ordering: receiving orders, checking stock items, and making sales orders. Consumers: make orders, receive invoices, make payments, and receive ordered products.

Figure 8 explains more specifically the business architecture in the sales model. In the sales model at MSMEs, there are three main actors who play a role in the sales process including customers or consumers, sales, and the owner or owner of the MSMES. Figure 8 describes the standard model of the sales process for MSMEs. 


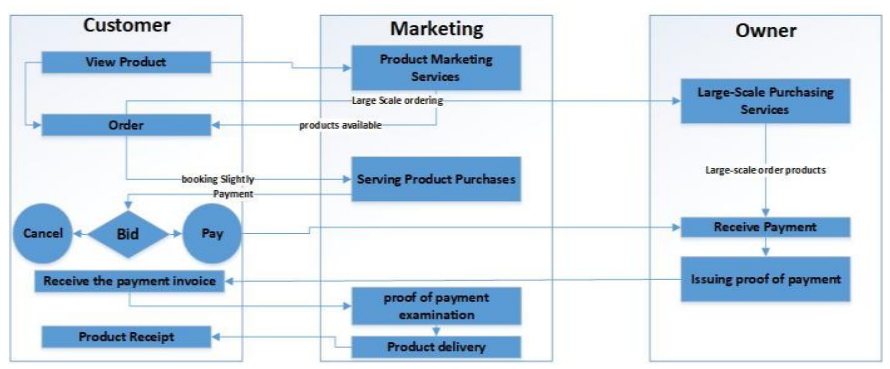

Fig. 8. Sales transaction activity of Production Results

The transaction model used in Figure 8 is a standard model in the process of selling the results of the processing industry where all transaction processes have not implemented a sales information system. This process still has shortcomings in the sales results reporting system so that production control is not balanced with sales results. To overcome this problem, an information system that is more capable of organizing the entire sales transaction process is implemented. For the sales activity system design can be seen in Figure 3.

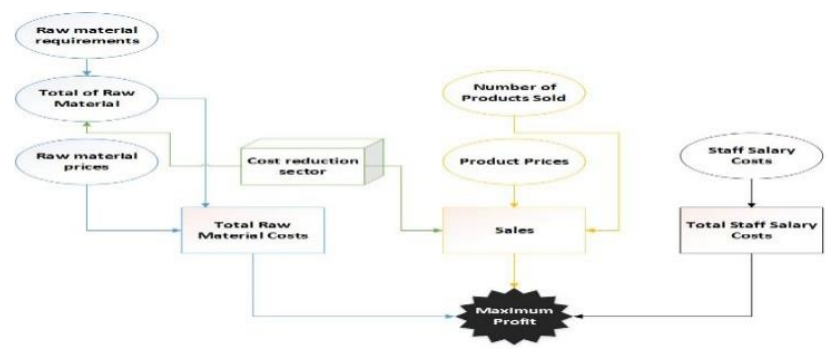

Fig. 9. Business Profit Architecture

Figure 9 describes the business profit architecture. In this case, an important sector in the line of production costs and production results must be considered in order to achieve maximum profit. In figure 9 cost reduction for maximum profit purposes can be applied to the sales sector and the quantity of raw materials. The purpose of business architecture is to define the applications required for processing data. Based on the initial business architecture standard, further development will be carried out as seen from the gap to be used as input for more complex development in terms of information systems.

\section{v. Information Systems Architecture}

In this phase, it will explain the architecture or the goal of maximum profit from the sales sector. The process of transferring the sales architecture into a corporate information system is expected to be able to control the production process by looking at certain types of products produced that are more salable in the market, and able to overcome other business problems such as financial data, more structured goods data and other things. Transaction activity processes and ERD business process data diagrams at MSMEs can be seen in Figure 3 and Figure 2.

\section{vi. Technology Architecture}

In this phase, the structure of technological architecture design that can be applied in MSMEs can be seen in Figure 6. In Figure 10, it is explained about the application of technological architectural application designs.

Based on the principles of technology architecture, the selection of the operating system must be adjusted to the admin's ability to operate.To implement database management, you can use Oracle system or MySQL. Whereas hardware that can be used are servers, switches, PCs / laptops and for system security a firewall can be used for network security, authentication, authority and granting access rights to applications and networks.

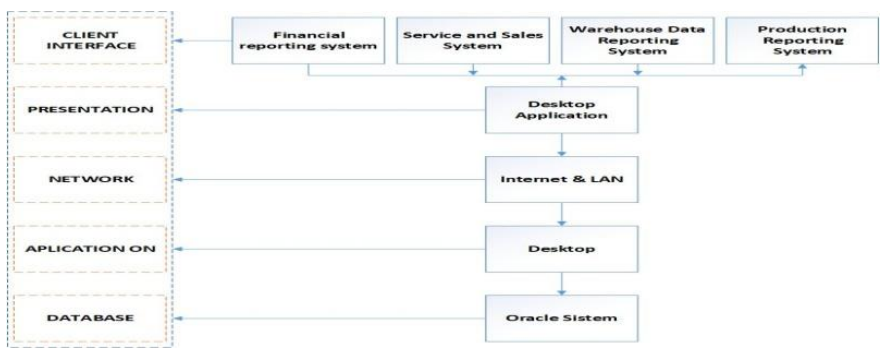

Fig. 10.Description of the technology architecture Application

\section{vii. Opportunities and Solutions}

Develop an overall strategy, determine what to buy, build or reuse, and how to implement the architecture described at the Technology Architecture stage.

viii. Migration Planning

In this phase, a planned migration will be carried out. The two functions of migration planning are:

a) Perceived of Usefulness (POU): knowing the benefits and how transferring information systems can increase organizational productivity.

b) Perceived Ease of Use (PEOU): feel the ease in operating information systems.

TABLE II. BUSINESS PROCESS MIGRATION PLANNING

\begin{tabular}{|l|l|l|}
\hline Migration Planning & Period of time & \multicolumn{1}{c|}{ Target } \\
\hline Attitute Change & short & $\begin{array}{l}\text { changes in employee attitudes } \\
\text { towards the new rules that have been } \\
\text { implemented }\end{array}$ \\
\hline Behavioral Change & short & $\begin{array}{l}\text { behavior change to perform tasks } \\
\text { based on new rules }\end{array}$ \\
\hline Life-Cycle Change & long & $\begin{array}{l}\text { guiding changes in business patterns } \\
\text { of each employee by business leaders }\end{array}$ \\
\hline $\begin{array}{l}\text { normative change } \\
\text { and administrative } \\
\text { change }\end{array}$ & short & $\begin{array}{l}\text { change to a more structured work } \\
\text { procedure according to standard } \\
\text { operating procedures }\end{array}$ \\
\hline
\end{tabular}


In accordance with its function, planning migration can be used in the process of implementing an enterprise architecture so that it can run optimally. The application of initial migration planning can be done through human resource management in accepting changes in work patterns and functions. Several steps of HR management can be seen in table 2.

\section{ix. Governance Implementation}

At this stage, it aims to determine the preparation and suitability of the initial plans for the TOGAF process. The tools used are desktop application processing industrial information systems.

\section{x. Architecture Management Changes}

This phase describes changes in the management structure of the processing industry.

TABLE III: CHANGE MANAGEMENT STAGES

\begin{tabular}{|c|c|c|c|}
\hline No & $\begin{array}{c}\text { Change } \\
\text { Management Stages }\end{array}$ & Before & After \\
\hline 1 & \multicolumn{3}{|l|}{ Management Structure } \\
\hline & Recruitment process & $\begin{array}{l}\text { Based on } \\
\text { recommendations }\end{array}$ & Interview process \\
\hline & Division of tasks & Multi job desk & division by functions \\
\hline \multirow[t]{4}{*}{2} & \multicolumn{3}{|l|}{ Human Resources } \\
\hline & office hours & Not yet scheduled & scheduled \\
\hline & employee salary & $\begin{array}{l}\text { below the minimum } \\
\text { wage }\end{array}$ & $\begin{array}{l}\text { according to minimum } \\
\text { wage standards }\end{array}$ \\
\hline & Bonus & Not available & based on overtime hours \\
\hline \multirow[t]{3}{*}{3} & \multicolumn{3}{|l|}{ Finance } \\
\hline & Financial reports & Not updated regularly & updated regularly \\
\hline & separation of capital & $\begin{array}{l}\text { not yet separate in } \\
\text { function and usability }\end{array}$ & $\begin{array}{l}\text { separate in function and } \\
\text { usability }\end{array}$ \\
\hline \multirow[t]{2}{*}{4} & \multicolumn{3}{|l|}{ Warehouse } \\
\hline & $\begin{array}{l}\text { warehouse data } \\
\text { reports }\end{array}$ & Not updated regularly & Updated regularly \\
\hline
\end{tabular}

The framework presented can be compared with 5 phases commonly used in live cycle management models including Planning, Analysis, Design, Implementation, and Maintenance. Judging from the planning phase, Zachman Framework and TOGAF Framework both have a planning stage in the process of building an enterprise framework. The difference is only in the characteristics of the planning development. Zachman is more detailed in the planning aspect than TOGAF. In the Analysis, Design and Implementation phase, TOGAF has principles in making decisions, provides guidance in the development of information technology, and supports architectural principles in design implementation. Meanwhile, in these phases Zachman is not very strong or detailed in its application. In the maintenance aspect, TOGAF has a maintenance aspect in its working framework, although it is not very effective, while the Zachman framework does not have a maintenance phase.
Another comparison is on the side of architectural evolution and architectural design. In terms of architectural evolution, the Zachman framework does not support changes or evolution of the architecture that has been built, while the TOGAF framework supports the evolutionary process because in the TOGAF architecture there is a planning migration phase or architectural change planning. In terms of the level of architectural detail, Zachman framework has a level of architectural detail that is less good than TOGAF. So in this study, the use of TOGAF is more recommended in the development of Enterprise Architecture, because TOGAF provides a more detailed and structured picture of the development of a framework so that if in the process of running the processing industry business there is a structural change in the business or a wider business development, the TOGAF framework can still be used by modifying a few parts that undergo changes without having to replace the entire framework of the current business.

\section{CONCLUSIONS}

Each Enterprise Architecture model cannot always be implemented properly and effectively in every type of business. How effective the application of the architectural model is depends on the characteristics of the model itself and the goals and objectives of the organization to be achieved. In this study, an experiment was conducted on the implementation of the enterprise architecture model, the Zachman framework and the TOGAF-ADM framework. Based on the results of implementing the architecture at MSMEs, the framework model that is considered effective to be applied to MSMEs is the TOGAF framework. The reason for determining is based on a more detailed architectural design process and architectural development can be carried out if changes occur in the future. This is in line with the processing industry business model which in a short period of time can develop from a small industrial scale to a large industrial scale. Another thing is that when compared to Zachman TOGAF is one of the most comprehensive frameworks with regards to the actual processes involved. The TOGAF Framework also provides guidance towards principles for decision making, IT resource guidelines, and architectural principles. Future research is expected to be able to design an Enterprise Architecture information system for Smart MSMEs.

\section{REFERENCES}

[1] J. A. Zachman, "A framework for information systems architecture," IBM Syst. J., vol. 38, no. 2.3, pp. 454-470, 1999, doi: 10.1147/sj.382.0454.

[2] F. Ahlemann, E. Stettiner, and M. Messerschmid, Strategic Enterprise Architecture Management. Springer International Publishing, 2012.

[3] J. N. Luftman, P. R. Lewis, and S. H. Oldach, "Transforming the enterprise: The alignment of business and information technology strategies," IBM Syst. J., vol. 32, no. 1, pp. 198-221, 2010, doi: 10.1147/sj.321.0198. 
[4] D. Goerzig and T. Bauernhansl, "Enterprise Architectures for the Digital Transformation in Small and Medium-sized Enterprises,"

Procedia CIRP, vol. 67, pp. 540-545, 2018, doi:

10.1016/j.procir.2017.12.257.

[5] BPS dan Kemenkop, "Perkembangan Data Usaha Mikro, Kecil, dan Menengah (UMKM) 2016-2017,”no. 1, pp. 2016-2017, 2017.

[6] United Nations, International Standard Classification of All

Economic Activities (ISIC). 2008.

[7] Kementerian Keuangan Republik Indonesia, "Kebijakan Antisipasi Krisis Tahun 2012 Melalui Program Kredit Usaha Rakyat,” 2012.

[8] LPPI, Profil Bisnis Usaha Mikro, Kecil dan Menengah (UMKM). 2015.

[9] J. A. Zachman, "John Zachman's Concise Definition of the Enterprise Framework," p. 2008, 2008.

[10] J. Lapalme, A. Gerber, A. Van Der Merwe, J. Zachman, M. De Vries, and K. Hinkelmann, "Exploring the future of enterprise architecture: A Zachman perspective," Comput. Ind., vol. 79, pp. 103-113, 2016, doi: 10.1016/j.compind.2015.06.010. 